University of Nebraska - Lincoln

DigitalCommons@University of Nebraska - Lincoln

November 2006

\title{
AN OVERVIEW OF THE CLASSIFICATION AND EVOLUTION OF THE MAJOR SCARAB BEETLE CLADES (COLEOPTERA: SCARABAEOIDEA) BASED ON PRELIMINARY MOLECULAR ANALYSES
}

Andrew B. T. Smith

University of Nebraska - Lincoln, asmith@unl.edu

David C. Hawks

University of California, Riverside, CA

John M. Heraty

University of California, Riverside, CA

Follow this and additional works at: https://digitalcommons.unl.edu/entomologypapers

Part of the Entomology Commons

Smith, Andrew B. T.; Hawks, David C.; and Heraty, John M., "AN OVERVIEW OF THE CLASSIFICATION AND EVOLUTION OF THE MAJOR SCARAB BEETLE CLADES (COLEOPTERA: SCARABAEOIDEA) BASED ON PRELIMINARY MOLECULAR ANALYSES" (2006). Papers in Entomology. 121.

https://digitalcommons.unl.edu/entomologypapers/121

This Article is brought to you for free and open access by the Museum, University of Nebraska State at DigitalCommons@University of Nebraska - Lincoln. It has been accepted for inclusion in Papers in Entomology by an authorized administrator of DigitalCommons@University of Nebraska - Lincoln. 


\title{
An Overview of the Classification and Evolution of the Major Scarab Beetle Clades (Coleoptera: Scarabaeoidea) Based on Preliminary Molecular Analyses
}

\author{
Andrew B. T. SMith \\ Canadian Museum of Nature \\ P.O. Box 3443 \\ Station D, Ottawa, K1P 6P4, CANADA \\ asmith@mus-nature.ca \\ AND \\ David C. Hawks and John M. Heraty \\ Department of Entomology \\ University of California \\ Riverside, CA, 92521, U.S.A. \\ david.hawks@ucr.edu and john.heraty@ucr.edu
}

\begin{abstract}
We present a preliminary overview of our molecular phylogenetics research on the superfamily Scarabaeoidea. The molecular data consists of $28 \mathrm{~S}$ ribosomal DNA sequences (mainly D2 and D3 expansion regions) for over 600 taxa and 18S ribosomal DNA sequences (mainly E17 to E35 expansion regions) for over 150 representative taxa within the lineages sampled. Based on our preliminary molecular phylogenetic results, Scarabaeoidea includes three major groups: 1) Geotrupidae, Passalidae, and Pleocomidae; 2) Lucanidae, Diphyllostomatidae, Trogidae, and Glaresidae; and 3) Hybosoridae, Ochodaeidae, Glaphyridae, and Scarabaeidae. The broad evolutionary patterns within the Scarabaeoidea are discussed with respect to phylogeny and evolution.
\end{abstract}

Twenty-four years ago, Henry Howden published the very first phylogenetic analysis of the Scarabaeoidea based on the principles of cladistics (Howden 1982). Since then, there have been numerous other attempts to reconstruct the evolutionary history of the Scarabaeoidea (most notable are the efforts of Browne and Scholtz 1995, 1996, 1998, 1999), as well as many astronomical leaps in our ability to compile and analyze morphological and molecular data for the purposes of phylogenetics. In this paper, we introduce our attempts to reconstruct the phylogeny of the Scarabaeoidea using molecular data, and we compare our preliminary results to previous studies. We recognize that our current state of scarab systematics is a community effort that has been built through time, and that achievements are made by standing on the shoulders of the pioneers who made the first forays into new areas of systematics research. With this in mind, and to honor his long and innovative career, we dedicate this paper to Henry Howden.

For the past five years, we have been conducting research on the molecular phylogenetics of the superfamily Scarabaeoidea. During that time, we have accumulated 28S ribosomal DNA sequences for over 600 taxa and 18S ribosomal DNA sequences for over 150 representative taxa within the lineages sampled. We have attempted to sample all major Scarabaeoidea lineages worldwide in order to get as complete a picture as possible of the phylogeny, evolution, and biogeographical patterns of scarab beetles. Numerous outgroup taxa also have 
been sampled in order to test the monophyly of Scarabaeoidea and to place this clade within the rest of the Coleoptera (these results are the subject of Hawks et $a l$., in prep.). The purpose of the present paper is to summarize all of this research and provide comments on the overall picture of the current state of Scarabaeoidea phylogeny and classification. Our preliminary findings also are compared to previous work on scarab phylogeny and classification.

Based on our research, we have found that many of the long-standing ideas about scarab phylogeny are supported by the molecular data, but there are several notable exceptions. There also are many scarab lineages that have been poorly known or inadequately studied and have never been definitively classified among the other scarab groups. In this paper, we present an overview of our findings covering the major lineages of Scarabaeoidea (Fig. 1).

The phylogenetic results presented in this paper are summarized and simplified from the research reported in detail in three separate papers that currently are in preparation. Hawks et al. (in prep.) examine the monophyly and placement within Coleoptera of the Scarabaeoidea using sequence data from over 600 Scarabaeoidea taxa and about 30 non-Scarabaeoidea taxa. Hawks et al. (in prep.) detail the methods used for this molecular phylogenetics research project and analyze sequence data from over 250 Scarabaeoidea taxa (focusing on all taxa except the phytophagous clade). Smith and Hawks (in prep.) examine the megadiverse phytophagous clade of scarab beetles using sequence data from over 350 taxa.

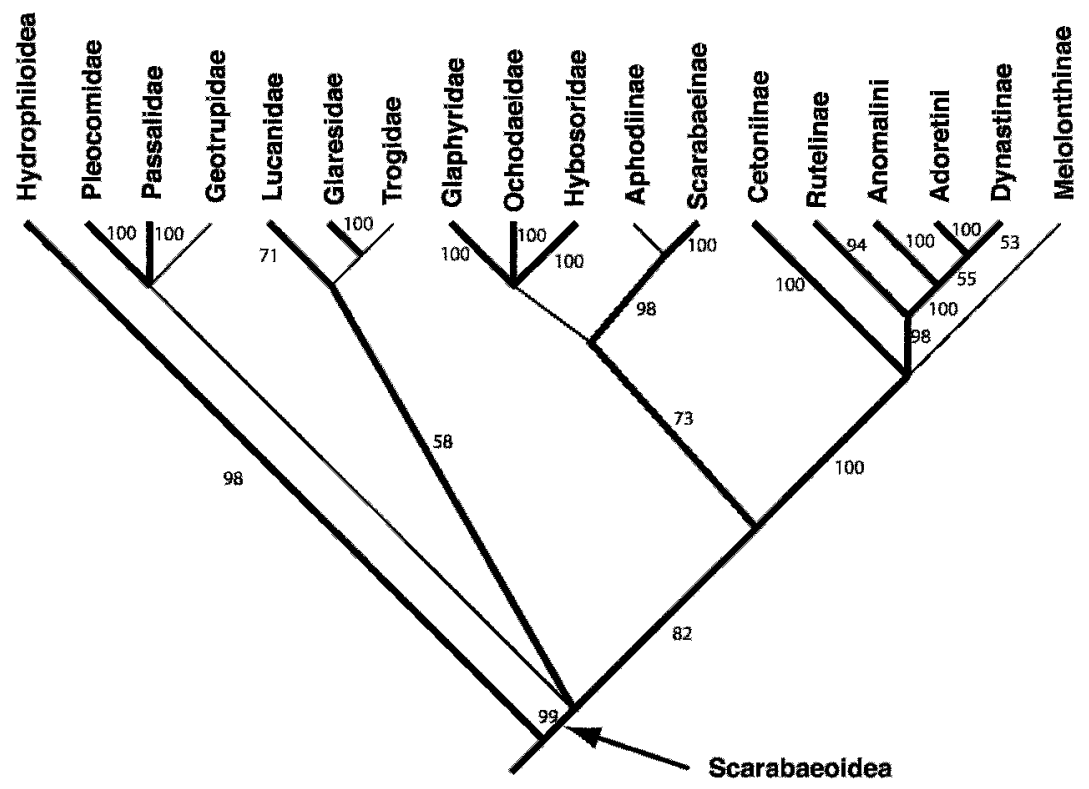

Fig. 1. Preliminary phylogenetic tree of the Scarabaeoidea based on molecular data. Collapsed branches indicate no support or very weak support in all analyses, thin branches indicate weak bootstrap support, and thick branches indicate strong support. Bootstrap values are from an analysis of the entire dataset. Terminal taxa depicted represent 4-140 species that were sequenced. 


\section{Methods}

\section{Taxon Selection}

Our preliminary molecular analyses are based on over 600 scarabaeoid and outgroup taxa from which we have sequenced 28S and 18S rDNA. Within Scarabaeoidea, we chose several representatives each of almost all major families and subfamilies (except the several that we have not yet been able to sequencelisted below), plus representatives of numerous tribes known to contribute to the diversity within subfamilies. Outgroup taxa include 13 members of the Hydrophilidae, representing 7 subfamilies and 13 genera. Based on $28 \mathrm{~S}$ and 18S rDNA evidence (Hawks et al., in prep.) we hypothesize that Hydrophiloidea is the sister group of Scarabaeoidea.

Our molecular phylogenetics research on Scarabaeoidea is an ongoing project. Although we have been successful in sequencing representative taxa from almost all major groups, we have not sequenced any taxa from the following extant Scarabaeoidea families and subfamilies, and therefore these groups are not dealt with in this paper: Belohinidae; Chaetocanthinae (Ochodaeidae); and Aulonocneminae, Dynamopodinae, Eremazinae, Phaenomeridinae, and Termitotroginae (Scarabaeidae).

\section{DNA Extraction, Sequencing, and Analysis}

The majority of DNA extractions were from fresh-frozen adult beetles or individual legs removed from adults, with most stored in $95 \% \mathrm{EtOH}$ at $-80^{\circ} \mathrm{C}$. In several cases DNA was extracted from the legs of fresh frozen $\left(-80^{\circ} \mathrm{C}\right)$ larvae, or from dried, pinned museum specimens that were a few months to a few decades old. In all cases, DNA was extracted from leg or thoracic muscle tissue, thereby allowing for the vouchering of nearly complete specimens. DNA extractions were accomplished using typical phenol-chloroform methods as described by Babcock and Heraty (2000), or, more recently, using a Chelex ${ }^{\circledR}$ - Proteinase K technique (Cano and Poinar 1993, modified slightly by Hawks).

Voucher specimens for taxa sequenced for this project were databased, labeled as DNA voucher specimens, and stored appropriately for future use. Most voucher specimens are in the collections of the authors and stored at $-80^{\circ} \mathrm{C}$ at the University of California, Riverside, and at the Canadian Museum of Nature. Others are stored in the University of Nebraska State Museum tissue collection at $-80^{\circ} \mathrm{C}$. Sequences will be submitted to the GenBank database at the time of publication of the first two exhaustive papers based on our Scarabaeoidea "megamatrix" (Hawks et al., in prep. and Smith and Hawks, in prep.).

Polymerase chain reaction (PCR) amplification protocol of $28 \mathrm{~S}$ and $18 \mathrm{~S}$ rDNA was as described in Babcock and Heraty (2000) and Heraty et al. (2004) using several primer pairs that will be listed in Hawks et al. (in prep.). PCR products were sequenced directly by the San Diego State University Microchemical Core Facility. Products were sequenced in both directions, and any differences between strands were resolved by eye. Sequence alignments were initially performed using Clustal (Thompson et al. 1997) and then further optimized manually. The aligned $28 \mathrm{~S}$ and 18S combined matrix used for the present project is 3530 base pairs in length. Preliminary analyses of our Scarabaeoidea data indicated that $28 \mathrm{~S}$ sequences are moderately conserved and are mostly effective for phylogenetic analyses at the generic to family levels and that $18 \mathrm{~S}$ is more highly conserved and informative at the family to order levels within Coleoptera.

Parsimony analyses were performed using PAUP*4.0B10 (Swofford 2002) and TNT 1.0 (Goloboff et al. 2003). The 13 hydrophilid taxa were designated as the outgroup. Gaps were treated as missing data. Bootstrap support was calculated 
using PAUP*4.0ß10 with 1,000 replicates and two random addition searches per replicate.

\section{Higher Scarabaeoidea Phylogenetics and Classification}

Although there are several scarab classification schemes currently used in the literature, it is desirable to focus towards a universal system of classification that is based on evolutionary relationships while respecting historical precedence. It also is appropriate to harmonize Scarabaeoidea classification with that of other superfamilies of Coleoptera. With these goals in mind, the scarab beetle classification schemes of Lawrence and Newton (1995) and Browne and Scholtz $(1995,1999)$ have been set as the standard for scarab taxonomists over the past decade. This $12-14$ family classification system is based on phylogenetic analyses and is constructed in the context of other Coleoptera. Our research on the molecular phylogenetics of scarab beetles gives us the opportunity to scrutinize this classification system using a new data set.

The 12-14 family Scarabaeoidea classification system of Lawrence and Newton (1995) and Browne and Scholtz (1995, 1999) place major clades such as Geotrupidae, Passalidae, Lucanidae, Trogidae, and Hybosoridae in separate families while lumping all of the dung scarabs (Aphodiinae, Scarabaeinae, etc.) and phytophagous scarabs (Melolonthinae, Cetoniinae, Rutelinae, Dynastinae, etc.) into the family Scarabaeidae. Scholtz and Chown (1995) provided discussion and justification for doing this by using the phylogeny of Browne and Scholtz (1995) and the known fossil record of scarabs to hypothesize that this entire clade evolved during the Tertiary. Scholtz and Chown (1995) attempted to stabilize Scarabaeoidea classification by considering the major clades that originated in the Mesozoic as families while those that originated in the Tertiary were relegated to subfamily or tribal rank. However, Krell (2000), Davis et al. (2002), Smith (2002), Philips et al. (2004), and others have since provided biogeographical or fossil evidence that the dung scarab clade and the phytophagous scarab clade both originated and diversified in the Cretaceous, not the Tertiary. Based on the contradictions in the date of origin for some lineages of scarab beetles and the availability of a new and more detailed phylogenetic analysis for the superfamily, we feel that it is appropriate and possible to re-examine and modify higher scarabaeoid classification.

Below, each of the major clades of Scarabaeoidea are listed and discussed in the context of our preliminary molecular phylogenetic analyses. Comparisons are made to previous phylogenetic hypotheses and to some of the historical placements of some groups. We also discuss some classification changes that seem to be necessary based on our results. These changes will improve higher scarabaeoid classification by making it more parallel to the evolution of the major scarab clades. A preliminary, simplified tree with hypothetical relationships of major scarabaeoid groups (families and a few selected subfamilies) is presented in (Fig. 1). Weakly supported branches are indicated with thin lines, moderately to strongly supported branches are indicated with thick lines.

\section{The Geotrupid Clade-Geotrupidae, Passalidae, and Pleocomidae}

Based on our preliminary analyses, Geotrupidae (including Bolboceratinae), Passalidae, and Pleocomidae form a weakly supported clade, but the exact relationships between the taxa in these families is inconclusive. This group may include the earliest lineages originating from the base of the scarabaeoid clade. 
However, it will be necessary to acquire more phylogenetic data in order to address this possibility. Passalidae and Pleocomidae both form strongly supported clades, but for the family Geotrupidae (including Bolboceratinae), the results are too inconclusive to determine if this family is monophyletic. All of the problem taxa currently are classified in the subfamily Bolboceratinae. This subfamily consists of numerous highly divergent taxa that may or may not form a monophyletic group. The other two geotrupid subfamilies (Geotrupinae and Taurocerastinae) do form strongly supported clades, although usually not as sister groups.

The composition of the family Geotrupidae has been the subject of recent debate. Scholtz and Browne (1996), using 30 morphological characters, found the Bolboceratinae to be "morphologically unique" from the other subfamilies of Geotrupidae, and they elevated this subfamily to the family level. Parallel analyses based on hind wing characters supported the splitting of these groups (Browne and Scholtz 1995, 1996, 1999). In fact, the authors found that in their phylogenetic analyses, the Geotrupidae came out in a clade with Hybosoridae, Ceratocanthidae, and Ochodaeidae, while the Bolboceratinae came out in a different clade with Pleocomidae, Lucanidae, Passalidae, Trogidae, and some other smaller scarabaeoid families. More recently, Verdú et al. (2004) used 38 larval morphology characters to reconstruct a phylogeny of Geotrupidae (including Bolboceratinae). They reported that there was strong support for the monophyly of the family (including Bolboceratinae). However, Verdú et al. (2004) only included one additional scarabaeoid ingroup family (Trogidae), and they used only Pleocomidae as an outgroup in the analysis to test the monophyly of the group. A true test of monophyly for Geotrupidae must include an array of taxa from the Lucanidae, Passalidae, Hybosoridae, Pleocomidae, etc. Our results contradict the findings of Browne and Scholtz $(1995,1996,1999)$ and Scholtz and Browne (1996) in that the taxa considered to be in the Bolboceratinae are related to, and may form the sister clade/s of, the taxa considered to be in the Geotrupinae and/or Taurocerastinae. However, more work is necessary to determine if the family Geotrupidae (and more specifically, the subfamily Bolboceratinae) is monophyletic.

Although there is no doubt that the family Passalidae is monophyletic, it does contain highly divergent taxa relative to most other scarabaeoid groups. This divergence makes it difficult to determine exactly where the family should be placed relative to other major groups of scarabaeoids. More research is needed to determine if Passalidae is nested within the Geotrupidae clade (or grade) or if the Passalidae lineage originated independently of the Geotrupidae lineage in the evolution of the scarabaeoids.

Pleocomidae is another strongly supported clade that is associated with the Geotrupidae lineage. As with the Passalidae, more work is needed to determine if this group originated within or independently from the Geotrupidae.

\section{The Lucanid Clade-Lucanidae, Diphyllostomatidae, Trogidae, and Glaresidae}

Lucanidae, Diphyllostomatidae, Trogidae, and Glaresidae are all closely related and together form a clade. The existence of this clade is unexpected based on the results of previous phylogenetic work on Scarabaeoidea and on the historic concepts of scarab classification based on morphological studies. Lucanidae has always been considered to be in a different lineage from Trogidae. Browne and Scholtz $(1995,1999)$ did have the two families (but not Glaresidae) in the same clade but not as sister taxa. Additionally, other families such as Passalidae, 
Glaphyridae, Pleocomidae, and Bolboceratidae also were placed in the same clade. Nonetheless, our preliminary molecular data support the monophyly of the Glaresidae + Trogidae + Lucanidae + Diphyllostomatidae clade. More research is needed to determine the exact relationship between these groups and to examine morphological characters that might also support this phylogenetic pattern.

In our preliminary analysis, Lucanidae is split into two strongly supported clades. One clade contains all of the groups that morphologically do not fit the common perception of the group, such as Aesalinae, Syndesinae, and Lampriminae. Also included in this clade is the genus Diphyllostoma Fall, which presently is classified as Diphyllostomatidae, but is probably better placed as a subfamily within Lucanidae. The other major lucanid clade contains all of the more "typical-looking" stag beetles such as Lucanus Scopoli and Dorcus MacLeay.

Our molecular results provide strong evidence that the families Trogidae and Glaresidae are closely associated, contrasting with some recent views on the two groups. Historically the genus Glaresis Erichson was included in the Trogidae, but Scholtz et al. (1987) separated the genus into its own family. Scholtz et al. (1987, 1994) and Browne and Scholtz $(1995,1999)$ presented persuasive morphological evidence that Glaresidae is only remotely related to Trogidae and forms the sister clade of the rest of the Scarabaeoidea. However, in their phylogenetic studies of the Scarabaeoidea, Browne and Scholtz (1995, 1996, 1999) ordered their characters into primitive and derived states. After designating many of the character states found in Glaresidae as primitive, they concluded that Glaresidae "exhibit the generalized scarabaeoid state of all characters", and that there are no autapomorphic characters among the structures of the hindwing base (Browne and Scholtz 1996). However, if character states are analyzed as unordered, many are either autapomorphic or phylogenetically equivocal, making it difficult to make any strong conclusions about the phylogenetic placement of Glaresidae. It can be argued that taxa exhibiting generalized characters or without autapomorphic character states can be found anywhere in a phylogenetic tree, and these findings alone do not indicate that a group is "primitive" or "basal." It is possible that Glaresis should once again be included within the Trogidae, but additional phylogenetic research will be necessary before strong conclusions can be drawn regarding the evolutionary relationships among this assemblage of taxa.

\section{The Scarabaeid Clade-Hybosoridae (including Ceratocanthinae), Ochodaeidae, Glaphyridae, and Scarabaeidae}

In our preliminary analyses, the families Hybosoridae, Ochodaeidae, Glaphyridae, and Scarabaeidae are all strongly supported individually as clades and together form a strongly supported clade. This phylogenetic pattern is somewhat unexpected based on previous scarab beetle classifications, because Hybosoridae and Ochodaeidae in particular often are considered allied to families such as Geotrupidae and Trogidae (Howden 1982; Browne and Scholtz 1995, 1999). However, there is evidence for the monophyly of this clade, and our preliminary analysis also indicates that the other families in the Scarabaeoidea are highly divergent from any of these four families. Interestingly, this large clade consists of all of the scarabaeoids with two-part male genitalia as discussed by d'Hotman and Scholtz (1990) and Scholtz (1990). The evidence for the evolutionary relationships between these four families is weak and more research is needed to determine how they are related to one another. We predict that additional morphological data 
will augment the support for the Hybosoridae + Ochodaeidae + Glaphyridae + Scarabaeidae clade.

Our preliminary analysis provides very strong support that the family Hybosoridae is paraphyletic unless it includes the Ceratocanthinae. These findings are consistent with Grebennikov et al. (2004) and Ocampo (2006) who discussed this pattern in detail. The relationship between the families Hybosoridae, Ochodaeidae, and Glaphyridae is unresolved. In some of our preliminary analyses there is weak support for a Hybosoridae + Ochodaeidae sister-group relationship, while other analyses result in weak support for Glaphyridae and Ochodaeidae as sister groups. The Hybosoridae + Ochodaeidae relationship was demonstrated in past phylogenetic analyses based on morphological characters (Browne and Scholtz 1995, 1999). The inclusion of Glaphyridae within a clade including Hybosoridae is consistent with a previous phylogenetic study based on larval characters (Grebennikov et al. 2004) but is not consistent with the findings of Browne and Scholtz (1995, 1999), which are based primarily on structures found at the base of the hindwing. Browne and Scholtz $(1995,1999)$ found numerous characters supporting the inclusion of Glaphyridae in a separate clade with Lucanidae, Passalidae, Trogidae, and others. It is noteworthy that the exact relationship of the Glaphyridae is different between Browne and Scholtz (1995) based exclusively on hind wing structures and Browne and Scholtz (1999) based on a combined analysis of several morphological data sets. This is indicative of the problems associated with scoring morphological characters for such a highly modified group such as the Glaphyridae.

Another somewhat surprising discovery concerns the placement of the Lichniini. This poorly known group is endemic to Chile and consistently has been placed in the family Glaphyridae for over a century. However, our preliminary analysis clearly indicates that the Lichniini are far removed from the true glaphyrids and are actually members of the Melolonthinae. True glaphyrids are entirely Holarctic in distribution.

\section{The Phytophagous Scarab Clade-Melolonthinae, Cetoniinae, Dynastinae, Rutelinae, and Other Minor Subfamilies}

The phytophagous scarab clade is another group that has been almost universally accepted as a monophyletic group for over 150 years. Erichson (1847) was the first to recognize this group as the "Scarabaeides pleurosticti," and no rigorous studies since have dissented from this concept in scarab classification. Howden (1982) and Browne and Scholtz (1996, 1998), in their phylogenetic studies of scarab beetles, did find strong support for the monophyly of this clade. Our preliminary research based on molecular data corroborates the previous ideas of the monophyly of the phytophagous scarab clade including Melolonthinae, Cetoniinae, Rutelinae, Dynastinae, and a few other much smaller subfamilies. Relationships within this clade however have been poorly studied. The four major subfamilies, Melolonthinae, Cetoniinae, Rutelinae, and Dynastinae are generally believed to be monophyletic, but the exact relationships between these groups and among the other minor subfamilies in the family Scarabaeidae have been poorly understood. Browne and Scholtz (1998) used the suite of morphological characters from the base of the hindwing to reconstruct the phylogeny of this group. However, they used only very broad groupings for the terminal taxa and generally did not recover any resolution within the major subfamilies. 
Our preliminary analysis strongly supports the monophyly of a large clade that includes the hybosorid clade, the scarabaeine clade, and the clade of phytophagous scarabs. However, there is little support for the monophyly of the dung-feeding scarabs and the phytophagous scarabs together, which is required for the continued recognition of these groups within the same familyScarabaeidae. Based on the structure of the Scarabaeoidea phylogeny and the shared general phytophagous habits of the members of this clade, we find it desirable to recognize the phytophagous clade of Scarabaeoidea as a distinct family. This would require dividing Scarabaeidae (as defined by Scholtz 1990, Browne and Scholtz 1995, etc.) into two families: Scarabaeidae in a more restricted sense including only the primarily dung-feeding lineages (Aphodiinae and Scarabaeinae), and Melolonthidae including the primarily phytophagous lineages. The only other reasonable option would be to again include Hybosoridae, Ochodaeidae, and Glaphyridae in the family Scarabaeidae, but we do not see the utility of recognizing these groups together in one family because they are molecularly highly divergent, have very different morphological characteristics, feeding preferences, and natural histories. We also believe that recognizing these groups in different families is much more congruent with the currently accepted classification scheme for the rest of Scarabaeoidea (including Lucanidae, Trogidae, Geotrupidae, Passalidae, etc.). This will be the basis of research that is currently in preparation (Hawks et al.).

Howden (1982), Browne and Scholtz (1998), Jameson (1998), and others have found evidence that Rutelinae and Dynastinae form a clade, but there has been little attempt to determine the exact relationship between these subfamilies. Jameson (1998) did a phylogenetic analysis to examine the relationships between some Rutelinae groups and found that the delimitation between the subfamilies Rutelinae and Dynastinae was not as simple as previously thought, and that some taxa were misclassified in one of these subfamilies or the other. Our preliminary analysis confirms the previous finding that the subfamilies Rutelinae and Dynastinae together form a monophyletic group but our results within this clade are somewhat of a radical departure of long-held ideas of the relationships between and within these subfamilies. Most noteworthy is the strong support for two sister clades within the Rutelinae + Dynastinae clade. One sister group contains the "true rutelines" including most of the taxa traditionally placed in the tribes Rutelini, Anoplognathini, Geniatini, and Anatistini (formerly Spodochlamyini). Absent are the Anomalini and Adoretini, which are strongly supported as members of the other sister clade along with the clade of "true dynastines." Because of the strong support for this pattern, it is foreseeable that the tribes Anomalini and Adoretini will need to be elevated to the subfamily level. This classification change would be necessary to maintain the subfamily Rutelinae as a monophyletic group while respecting the traditional ideas about the composition of the Dynastinae and, at the same time, recognizing the distinctness of the Anomalini and Adoretini. It is also noteworthy that the genera Parastasia Westwood and Peltonotus Burmeister form a clade that is firmly placed in the subfamily Dynastinae as the sister clade to all of the other members of the subfamily. Both of these genera have a history of being placed by some authors in the subfamily Rutelinae.

The monophyly of the subfamily Melolonthinae has never been well established, with several taxa being pulled into or removed from the group by various authors, and vastly different classification schemes being used within the subfamily over the past 150 years. In fact, there is no single reference where 
a complete and modern tribal classification has been proposed, and there has been no attempt to reconstruct the phylogeny of this subfamily. Not surprisingly, our preliminary analysis has uncovered many relationships that had not been previously discussed in the literature and that contradict many other previously published classification ideas about Melolonthinae. With the current dataset, we are unable to confirm or refute the monophyly of the Melolonthinae. Various adjustments in the analysis parameters yield either a very weakly supported monophyletic Melolonthinae or, more commonly, a melolonthine grade originating at the base of the phytophagous scarab lineage. Without any conclusive results, it is desirable to maintain all of these taxa within the subfamily Melolonthinae until additional phylogenetically informative characters can be found to resolve the relationships and phylogenetic placement of melolonthines. Our results do confirm that several smaller taxa of scarab beetles have been misclassified and actually belong within the Melolonthinae clade (or grade). These include Lichniini (formerly a subfamily of Glaphyridae as discussed above) and Aclopinae, Allidiostomatinae, Euchirinae, Orphninae, and Pachypodinae (all currently subfamilies within Scarabaeidae). Also noteworthy is the hypothesized relationship of Systellopini, Oncerini, Sericini, and Hopliini firmly within the Melolonthinae. These taxa have been removed from this subfamily at various times, but our evidence strongly indicates that they belong among the other Melolonthinae. Recently, Ahrens (2006) conducted a phylogenetic analysis of the tribe Sericini and included numerous other Melolonthinae taxa. His results were informative within and near the Sericini clade but yielded inconclusive results for most of the rest of the Melolonthinae taxa in the analysis.

The subfamily Cetoniinae also has undergone taxonomic turmoil. Some authors choose to consider the tribes Trichiini and Valgini to be separate subfamilies from the Cetoniinae. Our preliminary findings reflect those of Browne and Scholtz (1998) with a strongly supported Cetoniinae clade containing both Valgini and Trichiini. The relationships within this clade have never been examined using modern phylogenetic methods. Our results indicate that the Valgini lineage is monophyletic and diverged early in the evolution of the cetoniines. The "true trichiine" lineage followed later, but we have found that the historical concept of this group renders the tribe paraphyletic. The tribe Trichiini should consist only of those taxa formerly placed in the subtribe Trichiina. The subtribes Osmodermatina and Incaina will need to be removed from the Trichiini and each elevated to the tribal level so that the classification within the subfamily better reflects the evolutionary relationships. These two groups, along with all of the other non-Valgini and non-Trichiini Cetoniinae taxa, form a strongly supported clade.

\section{The Dung Beetle Clade-Scarabaeinae and Aphodiinae}

It is universally assumed that the dung beetle subfamilies Scarabaeinae and Aphodiinae are sister taxa. Although each of these subfamilies has been the subject of recent phylogenetic research, there has been no formal attempt to look at the exact relationship between these subfamilies and to test the monophyly of each group. Browne and Scholtz (1998) included these subfamilies in their phylogenetic analysis of the family Scarabaeidae and found an impressive number of characters supporting the monophyly of Scarabaeinae + Aphodiinae (including Aegialiinae and Aulonocnemis Klug). However, they did not include specific genera or tribes as terminal taxa and thus did not test the monophyly of each of these groups. Philips et al. (2004) performed a phylogenetic analysis of the 
Scarabaeinae using morphological characters but did not include enough Aphodiinae in their analysis to produce any significant conclusions about the relationship between the two subfamilies. Villalba et al. (2002) and CabreroSañudo and Zardoya (2004) both looked at the molecular phylogeny of Iberian "dung beetles" and Aphodiini respectively but did not include enough taxa to adequately test the monophyly of these groups as a whole or place the lineages within the classification of worldwide taxa with much accuracy. In our preliminary analysis we found strong support for the monophyly of the dung beetle clade (Scarabaeinae + Aphodiinae). This corroborates the results of previous morphological research. However, the relationship between the two subfamilies is not as simple as previously thought. Our analysis shows the subfamily Aphodiinae to be a grade, not a clade, with several independent lineages originating prior to the evolution of the true dung beetles (Scarabaeinae). The Scarabaeinae on the other hand, is a strongly supported clade. It seems likely that it will be appropriate to recognize additional subfamilies among some of the major lineages presently classified as Aphodiinae.

\section{Acknowledgments}

We thank the following collaborators who have contributed expertise and resources to smaller, more detailed molecular taxonomic studies within the Scarabaeoidea: Mary Liz Jameson, Estefanía Micó, Federico Ocampo, and Matt Paulsen. We would also like to thank the many collectors who have provided us with DNA-quality specimens used in this research project, and other colleagues who have provided assistance with methodology and analyses. These individuals are acknowledged by name in Hawks et al. (in prep.) and Smith and Hawks (in prep.). ABTS would like to thank Henry Howden for igniting his interest in scarab beetles during his evolution and biogeography courses at Carleton University. Our molecular phylogenetics research was supported, in part, by an NSF/PEET grant (DEB0108245) to J.M. Heraty, a portion of the NSF Coleoptera Tree of Life grant (DEB0531768) provided to Heraty and Hawks, an NSF/BS\&I grant (DEB-0342189) to A.B.T. Smith and F.C. Ocampo, an NSF/PEET grant (DEB-0118669) to M.L. Jameson and B.C. Ratcliffe, an NSERC-PDF award to A.B.T. Smith, and our own resources.

\section{References Cited}

Ahrens, D. 2006. The phylogeny of Sericini and their position within the Scarabaeidae based on morphological characters (Coleoptera: Scarabaeidae). Systematic Entomology 31:113-144.

Babcock, C. S., and J. M. Heraty. 2000. Molecular markers distinguishing Encarsia formosa and Encarsia luteola (Hymenoptera: Aphelinidae). Annals of the Entomological Society of America 93:738-744.

Browne, D. J., and C. H. Scholtz. 1995. Phylogeny of the families of Scarabaeoidea (Coleoptera) based on characters of the hindwing articulation, hindwing base and wing venation. Systematic Entomology 20:145-173.

Browne, D. J., and C. H. Scholtz. 1996. Morphology of the hind wing articulation and wing base of the Scarabaeoidea (Coleoptera) with some phylogenetic implications. Bonner Zoologische Monographien 40:1-200.

Browne, D. J., and C. H. Scholtz. 1998. Evolution of the scarab hindwing articulation and wing base: a contribution toward the phylogeny of the Scarabaeidae (Scarabaeoidea: Coleoptera). Systematic Entomology 23:307-326.

Browne, D. J., and C. H. Scholtz. 1999. A phylogeny of the families of Scarabaeoidea (Coleoptera). Systematic Entomology 24:51-84.

Cabrero-Sañudo, F.-J., and R. Zardoya. 2004. Phylogenetic relationships of Iberian Aphodiini (Coleoptera: Scarabaeidae) based on morphological and molecular data. Molecular Phylogenetics and Evolution 31:1084-1100. 
Cano, R. J., and H. N. Poinar. 1993. Rapid isolation of DNA from fossil and museum specimens suitable for PCR. Biotechniques 15:432-436.

Davis, A. L. V., C. H. Scholtz, and T. K. Philips. 2002. Historical biogeography of scarabaeine dung beetles. Journal of Biogeography 29:1217-1256.

Erichson, W. F. 1847. Naturgeschichte der Insecten Deutschlands. Erste Abtheilung. Coleoptera. Volume 3, Lieferung 4, pp. 481-640. Nicolaischen Buchhandlung, Berlin.

Goloboff, P., J. S. Farris, and K. Nixon. 2003. TNT (Tree Analysis using New Technology), version 1 . Published by the authors, Tucumán, Argentina.

Grebennikov, V. V., A. Ballerio, F. C. Ocampo, and C. H. Scholtz. 2004. Larvae of Ceratocanthidae and Hybosoridae (Coleoptera: Scarabaeoidea): study of morphology, phylogenetic analysis and evidence of paraphyly of Hybosoridae. Systematic Entomology 29:524-543.

Heraty, J., D. Hawks, J. S. Kostecki, and A. Carmichael. 2004. Phylogeny and behaviour of the Gollumiellinae, a new subfamily of the ant-parasitic Eucharitidae (Hymenoptera: Chalcidoidea). Systematic Entomology 29:544-559.

d'Hotman, D., and C. H. Scholtz. 1990. Phylogenetic significance of the structure of the external male genitalia in the Scarabaeoidea (Coleoptera). Entomological Memoir of the Department of Agricultural Development, Republic of South Africa 77:1-51.

Howden, H. F. 1982. Larval and adult characters of Frickius Germain, its relationship to the Geotrupini, and a phylogeny of some major taxa in the Scarabaeoidea (Insecta: Coleoptera). Canadian Journal of Zoology 60:2713-2724.

Jameson, M. L. 1998. Phylogenetic analysis of the subtribe Rutelina and revision of the Rutela generic groups (Coleoptera: Scarabaeoidea: Rutelinae: Rutelini). Bulletin of the University of Nebraska State Museum 14:1-184.

Krell, F. T. 2000. The fossil record of Mesozoic and Tertiary Scarabaeoidea (Coleoptera: Polyphaga). Invertebrate Taxonomy 14:871-905.

Lawrence, J. F., and A. F. Newton. 1995. Families and subfamilies of Coleoptera (with selected genera, notes, references and data on family group names) [pp. 779-1006]. In: Biology, Phylogeny, and Classification of Coleoptera: Papers Celebrating the 80th Birthday of Roy A. Crowson. J. Pakaluk and S. A. Slipinski (eds.). Muzeum i Instytut Zoologii PAN, Warszawa, Poland.

Ocampo, F. C. 2006. Phylogenetic analysis of the scarab family Hybosoridae and monographic revision of the New World subfamily Anaidinae (Coleoptera: Scarabaeoidea). 3. Phylogenetic analysis of the subfamily Anaidinae (Coleoptera: Scarabaeoidea). Bulletin of the University of Nebraska State Museum 19:13-177.

Philips, T. K., E. Pretorius, and C. H. Scholtz. 2004. A phylogenetic analysis of dung beetles (Scarabaeinae: Scarabaeidae): unrolling an evolutionary history. Invertebrate Systematics 18:53-88.

Scholtz, C. H. 1990. Phylogenetic trends in the Scarabaeoidea (Coleoptera). Journal of Natural History 24:1027-1066.

Scholtz, C. H., and D. J. Browne. 1996. Polyphyly in the Geotrupidae (Coleoptera: Scarabaeoidea): a case for a new family. Journal of Natural History 30:597-614.

Scholtz, C. H., D. J. Browne, and J. Kukalová-Peck. 1994. Glaresidae, archaeopteryx of the Scarabaeoidea (Coleoptera). Systematic Entomology 19:259-277.

Scholtz, C. H., and S. L. Chown. 1995. The evolution of habitat use and diet in the Scarabaeoidea: a phylogenetic approach [pp. 356-374]. In: Biology, Phylogeny, and Classification of Coleoptera: Papers Celebrating the 80th Birthday of Roy A. Crowson. J. Pakaluk and S. A. Slipinski (eds.). Muzeum i Instytut Zoologii PAN, Warszawa, Poland.

Scholtz, C. H., D. d'Hotman, and A. Nel. 1987. Glaresidae, a new family of Scarabaeoidea (Coleoptera) to accommodate the genus Glaresis Erichson. Systematic Entomology $12: 345-354$.

Smith, A. B. T. 2002. Revision of the Southern South American endemic genus Aulacopalpus Guérin-Méneville with phylogenetic and biogeographic analyses of the subtribe Brachysternina (Coleoptera: Scarabaeidae: Rutelinae: Anoplognathini). Coleopterists Bulletin 56:379-437.

Swofford, D. L. 2002. PAUP*, version 4.0ß10. Sinauer, Sunderlund, Massachusetts. 
Thompson, J. D., T. J. Gibson, F. Plewniak, F. Jeanmougin, and D. G. Higgins. 1997. The ClustalX windows interface: flexible strategies for multiple sequence alignment aided by quality analysis tools. Nucleic Acids Research 25:4876-4882.

Verdú, J. R., E. Galante, J.-P. Lumaret, and F. J. Cabrero-Sañudo. 2004. Phylogenetic analysis of Geotrupidae (Coleoptera, Scarabaeoidea) based on larvae. Systematic Entomology 29:509-523.

Villalba, S., J. M. Lobo, F. Martín-Piera, and R. Zardoya. 2002. Phylogenetic relationships of Iberian dung beetles (Coleoptera: Scarabaeinae): insights on the evolution of nesting behavior. Journal of Molecular Evolution 55:116-126. 